Tersedia online di: http://ejournal-balitbang.kkp.go.id/index.php/bawal
e-mail:bawal.puslitbangkan@ gmail.com
BAWAL WIDYA RISET PERIKANAN TANGKAP
Volume 10 Nomor 1 April 2018
p-ISSN: 1907-8226
e-ISSN: 2502-6410
BAWAL
Nomor Akreditasi: 620/AU2/P2MI-LIPI/03/2015

\title{
KOMPOSISI JENIS, SEBARAN DAN KEPADATAN STOK UDANG PADA MUSIM SELATAN DI PERAIRAN TIMUR KALIMANTAN
}

\section{COMPOSITION, DISTRIBUTION AND STOCK DENSITY OF SHRIMPS DURING SOUTH MONSOON IN THE EAST KALIMANTAN WATERS}

\author{
Tirtadanu*1, Suprapto ${ }^{1}$ dan Andina R. Pane ${ }^{1}$ \\ ${ }^{1}$ Balai Riset Perikanan Laut, Kompl. Raiser Jl. Raya Bogor KM. 47, Cibinong, Jawa Barat, Indonesia \\ Teregistrasi I tanggal: 29 Mei 2017; Diterima setelah perbaikan tanggal: 12 Februari 2018; \\ Disetujui terbit tanggal: 13 Februari 2018
}

\begin{abstract}
ABSTRAK
Kajian tentang komposisi, sebaran dan kepadatan stok udang merupakan informasi penting sebagai evaluasi dampak aktivitas penangkapan udang saat ini. Penelitian ini bertujuan untuk mengkaji komposisi jenis, sebaran dan kepadatan stok udang pada saat musim selatan di perairan Timur Kalimantan. Penelitian dilakukan pada bulan September - Oktober 2016 menggunakan trawl pada Kapal Riset Baruna Jaya IV (tali ris atas 36 m). Lama penarikan jaring 1 jam dengan kecepatan kapal sekitar 3 knot. Analisis terhadap 11 stasiun pengamatan yang berhasil menunjukkan komposisi udang terdiri dari 14 spesies yang tergolong dalam 7 genera dan 3 famili. Spesies yang dominan meliputi udang dogol (Metapenaeus ensis), udang windu (Penaeus monodon) dan udang jerbung (Penaeus merguiensis). Berdasarkan lokasinya, kepadatan stok tertinggi ditemukan di sebelah timur Balikpapan dan secara umum kepadatan stok tertinggi ditemukan pada kedalaman kurang dari $40 \mathrm{~m}$. Kepadatan stok udang berkorelasi dengan kedalaman di mana udang jerbung hanya tertangkap pada kedalaman kurang dari $40 \mathrm{~m}$. Udang dogol ditemukan pada kedalaman hingga $60 \mathrm{~m}$ namun lebih padat pada kedalaman kurang dari 40 $\mathrm{m}$, sedangkan udang windu lebih padat pada perairan yang lebih dalam yaitu antara 40-60 $\mathrm{m}$. Total kepadatan stok udang pada musim selatan di perairan Timur Kalimantan adalah 16,5 $\pm 9,7 \mathrm{~kg} / \mathrm{km}^{2}$.
\end{abstract}

Kata Kunci: Komposisi; sebaran; kepadatan stok; udang; timur Kalimantan

\begin{abstract}
Study of species composition, distribution and stock density of shrimp was vital to evaluate of the impact of current shrimp fishing to its sustainability. The research aims to study composition, distribution and stock density of shrimps during south monsoon in the East of Kalimantan which was conducted in SeptemberOctober 2016 by conducting exploratory survey using trawling with R.V. Baruna Jaya IV (headrope length of 36 $m$ ). Towing duration of 1 hour and vessel speed around 3 knots. The result from 11 stations showed that the composition of shrimps consists of 14 species from 7 genera and 3 family. The dominant species (38.4\%) were greasyback shrimp (Metapenaeus ensis), while giant tiger prawn (Penaeus monodon) by $22.2 \%$ and banana prawn (Penaeus merguiensis) by 16.7\%. Based on the geographic location, the highest stock density was found in the eastern part of Balikpapan waters $(<40 \mathrm{~m}$ depth). The shrimp density found have association with depths where banana prawn found in depths of less than $40 \mathrm{~m}$. Greasyback shrimp found in depths of more than $60 \mathrm{~m}$ with more abundant in depth less than $40 \mathrm{~m}$, while giant tiger prawn was more abundant in deeper water in depths between $40-60 \mathrm{~m}$. Total density of shrimps during south monsoon in the eastern part of Kalimantan waters was $16.5 \pm 9.7 \mathrm{~kg} / \mathrm{km}^{2}$.
\end{abstract}

Keywords: Composition; distribution; stock density; shrimp; East Kalimantan 


\section{PENDAHULUAN}

Perairan Timur Kalimantan merupakan bagian dari Selat Makassar yang termasuk dalam Wilayah Pengelolaan Perikanan (WPP NRI) 713. Beberapa daerah di perairan Timur Kalimantan telah menjadi sentra perikanan udang diantaranya perairan Kotabaru, Paser, Balikpapan, Samarinda, Kutai dan Bontang. Perikanan udang tersebut telah diusahakan sejak lama dan aktivitas penangkapannya telah terlaporkan sejak tahun 1976 (Naamin \& Uktolseya, 1976).

Nelayan penangkap udang di perairan tersebut merupakan nelayan tradisional dan penangkapannya di daerah pantai dengan alat tangkap lampara dasar, trammel net dan jaring insang. Luas daerah penangkapan udang di perairan Timur Kalimantan diduga sebesar $54.000 \mathrm{~km}^{2}$ dan produksinya di tahun 2014 mencapai 31.126 ton (Naamin et al., 1991; Direktorat Jenderal Perikanan Tangkap, 2015). Jenis udang yang banyak diusahakan diantaranya udang dogol (Metapenaeus ensis), udang windu (Penaeus monodon) dan udang putih (Penaeus merguiensis).

Hasil tangkapan per unit upaya kapal perikanan udang di perairan Timur Kalimantan dilaporkan berfluktuatif dan peningkatan upayanya tidak selalu meningkatkan produksi bahkan cenderung mengalami penurunan karena telah mengalami kapasitas berlebih (over capacity) (Budiarti \& Mahiswara, 2012). Pengelolaan yang tepat diperlukan sebagai upaya menjaga keberlanjutan perikanan udang di perairan Timur Kalimantan. Salah satu informasi penting yang diperlukan sebagai evaluasi dampak penangkapan udang saat ini adalah informasi terkait komposisi, sebaran dan kepadatan stok udang.
Beberapa kajian stok udang di perairan timur Kalimantan telah dilakukan pada penelitian terdahulu. Berdasarkan penelitian dengan model holistik pada tahun 1993, laju pengusahaan udang di perairan Kalimantan Timur diketahui belum mencapai eksploitasi penuh (Suman et al., 1993). Kemudian penelitian di tahun 2009 dan 2010 dengan model analitik, tingkat pemanfaatan udang telah mencapai eksploitasi penuh (Suman \& Umar, 2010; Suman \& Bintoro, 2009). Kajian stok berupa komposisi, sebaran dan kepadatan stok udang di perairan Timur Kalimantan dilakukan dengan metode sapuan (swept area method) dibahas dalam tulisan ini dan diharapkan dapat digunakan untuk melengkapi informasi ilmiah untuk mendasari pengelolaan sumberdaya udang yang berkelanjutan di perairan Timur Kalimantan.

\section{METODEPENELITIAN}

Penelitian tentang stok udang dilaksanakan pada bulan September - Oktober 2016 dengan menggunakan wahana Kapal Riset Baruna Jaya IV berukuran 1.219 GT, panjang ( $\left.\mathrm{L}_{\mathrm{O}} \mathrm{A}\right)$ 60,4 m, lebar 12,1 $\mathrm{m}$ dan tinggi 6,5 m. Alat tangkap trawl yang digunakan memiliki ukuran mata jaring 4 inchi di bagian kantong. Panjang tali ris atas $36 \mathrm{~m}$ dan tali ris bawah $41 \mathrm{~m}$. Penelitian eksplorasi ini menggunakan metode sapu (swept area method) dengan alat trawl berukuran mata jaring dibagian kantong (cod-end mesh size) sebesar 4 inchi, panjang tali ris atas (head rope) $36 \mathrm{~m}$ dan tali ris bawah (ground rope) $41 \mathrm{~m}$. Lokasi penelitian yang diliput berada pada posisi geografis antara $116^{\circ} \mathrm{BT}-118^{\circ} \mathrm{BT}$ dan $4^{\circ} \mathrm{LS}-1^{\circ} \mathrm{LU}$ (Gambar 1). Pengambilan sampel dilakukan sebanyak 11 stasiun penelitian pada kedalaman antara 10 - 75 m. Lama penarikan jaring (hauling) setiap stasiun pengamatan adalah satu jam dengan kecepatan kapal waktu menarik jaring rata-rata 3 knot.

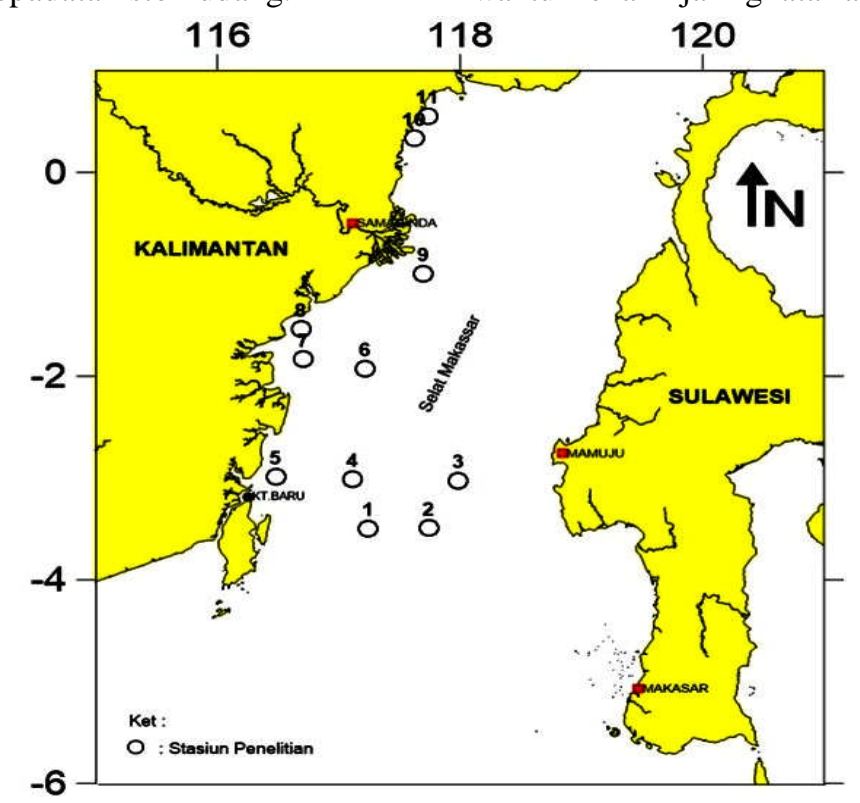

Gambar 1. Peta pengoperasian jaring trawl di Perairan Timur Kalimantan.

Figure 1. Map of trawl net operated in East Waters of Kalimantan. 
Sebaran stok udang dilakukan dengan cara memplotkan nilai kepadatan stok $\left(\mathrm{kg} / \mathrm{km}^{2}\right)$ setiap stasiun pengamatan pada peta. Kepadatan stok $\left(\mathrm{kg} / \mathrm{km}^{2}\right)$ dan laju tangkap $(\mathrm{kg} / \mathrm{jam})$ dianalisis tiap strata kedalaman perairan, yaitu $<40$, antara 40-60 m dan >60 m. Korelasi antara kepadatan stok dan kedalaman perairan dianalisis dengan ui korelasi Pearson. Identifikasi jenis udang yang tertangkap mengacu pada Carpenter \& Niem (1998).

Estimasi kepadatan stok udang menggunakan metode sapuan (Swept area) dengan luas area merupakan perkalian antara panjang sapuan dan lebar mulut jaring. Penghitungan indeks kepadatan stok yaitu (Sparre \& Venema, 1992):

$\alpha=V \times t \times h r \times \times 2 \times 1,852 \times 0,001$

$D=\left(\frac{1}{a}\right) x\left(\frac{c}{f}\right)$

Di mana: $\alpha=$ Luas sapuan $\left(\mathrm{km}^{2}\right) ; \mathrm{V}=$ Kecepatan tarikan jaring (knot); t=lama penarikan (jam); hr=panjang headrope (m); X2=fraksi panjang headrope sebesar 0,5 menurut Pauly (1980) sebagai lebar alur yang disapu oleh trawl; 1,852= konversi mil ke km; 0,001=konversi $\mathrm{m}$ ke km; $\mathrm{D}=$ kepadatan stok $\left(\mathrm{kg} / \mathrm{km}^{2}\right)$; c=laju tangkap $(\mathrm{kg} / \mathrm{jam})$; $\mathrm{f}=$ escapement factor sebagai dugaan proporsi ikan pada alur sapuan dan tertangkap jaring sebesar 0,5 (Saeger et al., 1976).

\section{HASIL DAN BAHASAN \\ Hasil}

\section{Komposisi Jenis}

Identifikasi jenis udang yang tertangkap trawl diperoleh 14 spesies dari 7 genera udang yang tergolong dalam 3 famili yaitu Penaeidae, Sicyoniidae dan Solenoceridae. Udang yang dominan tertangkap adalah famili Penaeidae dengan spesies udang dogol (Metapenaeus ensis) dengan proporsi 38,4\%, diikuti udang windu (Penaeus monodon) dengan proporsi 22,2\% dan udang jerbung (Penaeus merguiensis) dengan proporsi $16,7 \%$ dari total tangkapan udang (Tabel 1).

Tabel 1. Komposisi udang yang tertangkap trawl di perairan Timur Kalimantan, September-Oktober 2016 Table 1. Composition of shrimps caught by trawl in east Kalimantan waters, September-October 2016

\begin{tabular}{|c|c|c|c|c|c|}
\hline $\begin{array}{l}\text { Famili } \\
\text { Family }\end{array}$ & $\begin{array}{l}\text { Genera } \\
\text { Genus }\end{array}$ & $\begin{array}{l}\text { Spesies } \\
\text { Species }\end{array}$ & $\begin{array}{c}\text { Total N } \\
\text { (ekor) } \\
\text { Total N } \\
\text { (ind) } \\
\end{array}$ & $\begin{array}{l}\text { Total W } \\
(\mathbf{k g}) \\
\text { Total W } \\
(\mathrm{kg}) \\
\end{array}$ & $\begin{array}{l}\text { Persentase }(\%) \\
\text { Percentage }(\%)\end{array}$ \\
\hline \multirow[t]{12}{*}{ Penaeidae } & Penaeus & Penaeus monodon & 5 & 1,47 & 22,27 \\
\hline & & Penaeus merguensis & 37 & 1,10 & 16,66 \\
\hline & & Penaeus semisulcatus & 5 & 0,21 & 3,18 \\
\hline & & Penaeus longistylus & 2 & 0,06 & 0,91 \\
\hline & & Penaeus intermedius & 2 & 0,04 & 0,61 \\
\hline & & Penaeus japonicas & 1 & 0,03 & 0,45 \\
\hline & Metapenaeus & Metapenaeus ensis & 159 & 2,54 & 38,47 \\
\hline & & Metapenaeus affinis & 9 & 0,09 & 1,36 \\
\hline & & Metapenaeus intermedius & 1 & 0,02 & 0,30 \\
\hline & Metapenaeopsis & Metapenaeopsis stridulans & 197 & 0,78 & 11,81 \\
\hline & Trachypenaeus & Trachypenaeus spp. & 37 & 0,19 & 2,91 \\
\hline & Parapenaeus & Parapenaeus longipes & 2 & 0,01 & 0,15 \\
\hline Sicyoniidae & Sicyonia & Sicyonia lancifera & 4 & 0,01 & 0,15 \\
\hline Solenoceridae & Solenocera & Solenocera crassicornis & 42 & 0,05 & 0,76 \\
\hline \multicolumn{3}{|c|}{ Total } & 503 & 6,60 & 100,00 \\
\hline
\end{tabular}

Udang yang ukurannya relatif besar dan temasuk ekonomis penting umumnya tertangkap pada kedalaman kurang dari $60 \mathrm{~m}$. Udang windu jenis Penaeus monodon lebih banyak tertangkap pada kedalaman antara $40-60 \mathrm{~m}$. Udang jerbung ditemukan pada perairan kurang dari $40 \mathrm{~m}$ dan jarang diketemukan pada perairan yang lebih dalam. Demikan juga udang dogol lebih banyak ditemukan pada kedalaman kurang dari $40 \mathrm{~m}$ (Tabel 2).

\section{Sebaran}

Hasil pengamatan menunjukkan sebaran spasial udang di perairan Timur Kalimantan tidak menyebar rata pada tiap daerah penangkapan. Kepadatan stok udang tertinggi ditemukan di perairan sekitar timur Balikpapan (Gambar 2). 
Tabel 2. Komposisi udang berdasarkan kedalaman di perairan Timur Kalimantan

Table 2. Composition of shrimps by depths in east Kalimantan waters

\begin{tabular}{|c|c|c|c|}
\hline \multirow{3}{*}{$\begin{array}{l}\text { Spesies } \\
\text { Species }\end{array}$} & \multicolumn{3}{|c|}{$\begin{array}{c}\text { Persentase total W (\%) berdasarkan kedalaman } \\
\text { Percentage of total W }(\%) \text { by depths }\end{array}$} \\
\hline & $<40$ & $40-60$ & $>60$ \\
\hline & (m) & (m) & (m) \\
\hline Metapenaeus ensis & 27,26 & 11,21 & \\
\hline Penaeus monodon & 9,09 & 13,18 & \\
\hline Penaeus merguiensis & 16,66 & & \\
\hline Metapenaeopsis stridulans & 1,67 & 7,57 & 2,57 \\
\hline Penaeus semisulcatus & 3,18 & & \\
\hline Trachypenaeus spp. & 1,67 & 0,94 & 0,30 \\
\hline Metapenaeus affinis & 1,21 & & 0,15 \\
\hline Penaeus longistylus & 0,91 & & \\
\hline Solenocera crassicornis & & 0,76 & \\
\hline Penaeus intermedius & 0,61 & & \\
\hline Penaeus japonicus & 0,45 & & \\
\hline Metapenaeus intermedius & 0,30 & & \\
\hline Parapenaeus longipes & & & 0,15 \\
\hline Sicyonia lancifera & & 0,15 & \\
\hline Total & 63,01 & 33,81 & 3,18 \\
\hline
\end{tabular}

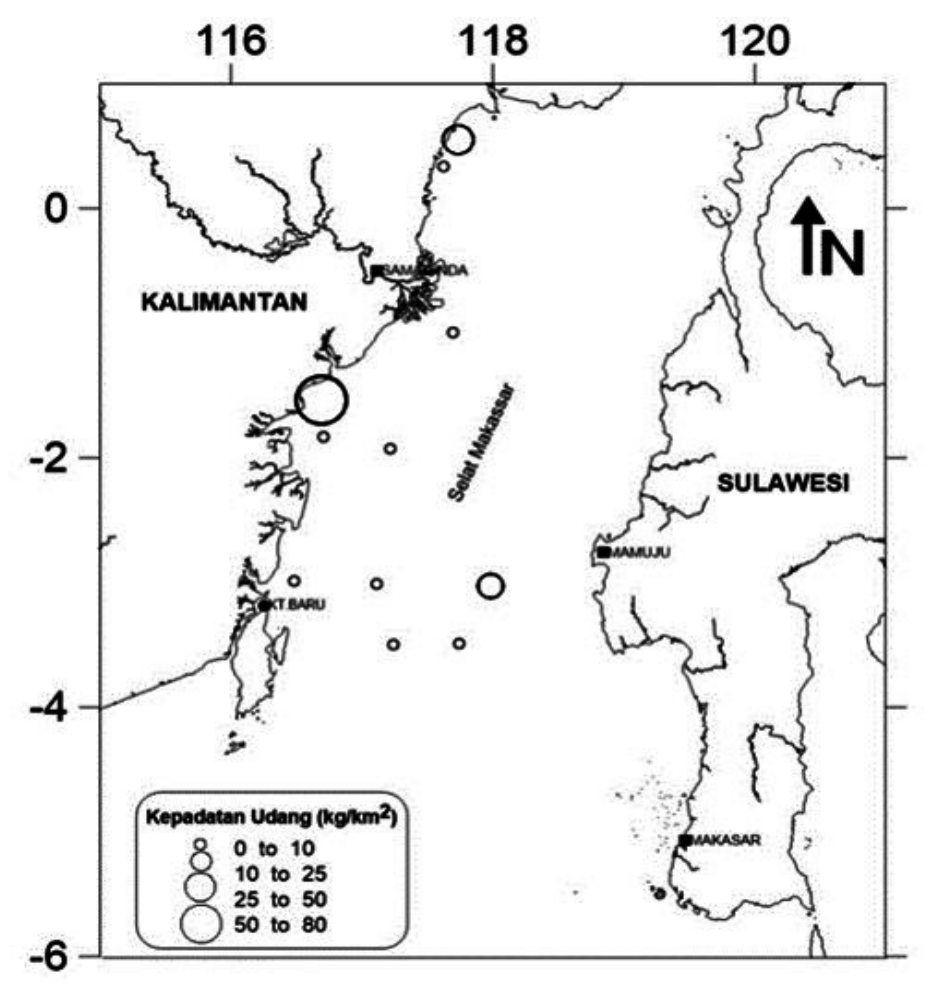

Gambar 2. Sebaran spasial udang di perairan Timur Kalimantan.

Figure 2. Spatial distribution of shrimps in East Kalimantan waters.

\section{Laju Tangkap dan Kepadatan Stok}

Diperoleh rata-rata laju tangkap udang dengan trawl sebesar 0,83 kg/jam. Hasil tangkapan tertinggi ditemukan pada kedalaman kurang dari $40 \mathrm{~m}$. Hasil perhitungan diperoleh rata-rata kepadatan stok udang $16,5 \mathrm{~kg} / \mathrm{km}^{2}$.
Berdasarkan uji korelasi Pearson, diperoleh hasil bahwa kepadatan stok udang berkorelasi dengan kedalaman (pada taraf á < 0,01). Kepadatan stok tidak menyebar rata pada setiap strata kedalaman. Kepadatan tertinggi (41,6 $\mathrm{kg} / \mathrm{km}^{2}$ ) terdapat pada kedalaman kurang dari $40 \mathrm{~m}$ dan terendah pada kedalaman lebih dari $60 \mathrm{~m}$ (Tabel 3). 
Tabel 3. Laju tangkap udang di perairan Timur Kalimantan

Table 3. Catch rate of shrimps in East Kalimantan waters

\section{Kedalaman (m)}

Rata-rata kepadatan udang

Average density of Shrimps

\section{Rata-rata laju tangkap udang}

Average catch rate of shrimps

\begin{tabular}{ccccc} 
Depth range $(\boldsymbol{m})$ & $\mathbf{W}\left(\mathbf{k g} / \mathbf{k m}^{2}\right)$ & $\mathbf{N}\left(\mathbf{i n d} / \mathbf{k m}^{\mathbf{2}}\right)$ & $\mathbf{W}$ ( $\mathbf{k g} / \mathbf{j a m})$ & $\mathbf{N}$ (ind/jam) \\
\hline$<40$ & 41,60 & 2680 & 2,08 & 134 \\
$40-60$ & 14,88 & 1233 & 0,74 & 62 \\
$>60$ & 1,40 & 333 & 0,07 & 17 \\
\hline
\end{tabular}

\section{Bahasan}

Udang yang tertangkap di perairan Timur Kalimantan terdiri dari 14 spesies yang tergolong dalam 7 genera dan 3 famili. Udang yang dominan tertangkap merupakan udang ekonomis penting yang tergolong dalam famili Penaeidae diantaranya udang dogol (Metapenaeus ensis), udang windu (Penaeus monodon) dan udang jerbung (Penaeus merguiensis). Menurut Naamin \& Uktolseya (1976), ketiga jenis udang tersebut merupakan spesies yang dominan tertangkap dengan trawl pada tahun 1976 dan tingkat pengusahaan pada saat itu sudah intensif. Pada periode penelitian ini, diperoleh proporsi tangkapan udang dogol $(38,4 \%)$ lebih tinggi dibandingkan udang jerbung (16,6\%). Disebutkan oleh (Pillai \& Diwan, 1997; Carpenter \& Niem, 1998), bahwa udang dogol umumnya memiliki kemampuan untuk beradaptasi terhadap fluktuasi parameter lingkungan perairan dan hidup pada rentang kedalaman yang lebih luas dibandingkan udang jerbung.

Kepadatan stok udang di Timur Kalimantan tidak merata secara spasial dan kedalaman. Perbedaan kepadatan stok secara spasial disebabkan oleh perbedaan kondisi lingkungan pada tiap daerah penangkapan. Kepadatan stok udang tertinggi ditemukan di perairan Balikpapan. Perairan Balikpapan memiliki kondisi perairan yang dangkal, bahan organik tinggi dan kandungan substrat dasar lumpur yang dominan sehingga merupakan habitat yang cocok bagi udang, khususnya genera Metapenaeus (Irawan \& Sari., 2013; Edrus et al., 2012; Macia, 2004).

Hasil analisis menyebutkan kepadatan stok udang di perairan Timur Kalimantan berkorelasi dengan kedalaman perairan, dimana kepadatan stok udang tertinggi ditemukan pada perairan relatif dangkal $(<40 \mathrm{~m})$. Peneliti lain (Pramonowibowo et al., 2007) memperoleh korelasi yang relatif rendah antara kepadatan stok udang dengan kedalaman di perairan Semarang pada kisaran 5-16 m. Hasil yang sama juga dikemukakan oleh Munga et al. (2013) di perairan Kenya yang memperlihatkan bahwa estimasi biomasa tertinggi pada musim timur laut dan tenggara berada pada kedalaman $<10$ m kemudian menurun pada kisaran kedalaman 10-20 m dan 20-40 m namun tidak ditemukan pada kedalaman 40-100 m. Udang windu ( $P$. monodon) dan udang dogol (M. ensis) di perairan Timur Kalimantan lebih banyak ditemukan pada perairan yang lebih dalam dibandingkan udang jerbung (P. merguiensis). Udang dogol ditemukan hingga kedalaman $60 \mathrm{~m}$ dan memiliki kepadatan tinggi pada kedalaman kurang dari 40 m. Udang windu lebih padat pada kedalaman antara 40-60 $\mathrm{m}$ dan udang jerbung pada kedalaman kurang dari $40 \mathrm{~m}$.

Hasil penelitian memperoleh rata-rata kepadatan udang di Timur Kalimantan sebesar 16,5 kg/ $\mathrm{km}^{2}$. Hasil ini lebih rendah dibandingkan udang di Laut Jawa $\left(21 \mathrm{~kg} / \mathrm{km}^{2}\right)$, Barat Sumatera $\left(53 \mathrm{~kg} / \mathrm{km}^{2}\right)$ serta udang windu di Laut Arafura $\left(110 \mathrm{~kg} / \mathrm{km}^{2}\right)$ (Tirtadanu et al., 2016; Nurulludin et al., 2016; Hargiyatno \& Sumiono, 2012). Kepadatan stok udang di perairan Timur Kalimantan lebih kecil dibandingkan beberapa perairan tersebut disebabkan sebagian besar perairan Selat Makassar merupakan perairan laut dalam sedangkan sebagian besar perairan Laut Jawa dan Arafura merupakan perairan dangkal dengan tingkat kesuburan yang tinggi dan berlumpur yang cocok bagi habitat udang (Somers, 1987). Kepadatan stok udang di suatu perairan dipengaruhi oleh faktor lingkungan (abiotik), tekanan penangkapan dan ada tidaknya predator (Promhom et al., 2015; Niamaimandi et al., 2007; Jonsdottir et al., 2012). Penangkapan udang yang dilakukan secara intensif di Kalimantan Timur diduga menjadi faktor utama rendahnya kepadatan stok udang. Untuk itu, masih perlu dilakukan pengkajian tentang pengaturan penangkapan udang antara lain melalui pembatasan jumlah alat tangkap, pelarangan menangkap pada musim pemijahan (close session), menentukan ukuran yang boleh ditangkap.

\section{KESIMPULAN}

Penelitian eksplorasi dengan Kapal Riset Baruna JayaIV di Timur Kalimantan khususnya di perairan antara Kotabaru dan Samarinda diperoleh 14 spesies udang penaeid yang tergolong kedalam 7 genera dan 3 famili. Spesies dominan adalah udang dogol (Metapenaeus ensis), diikuti oleh udang windu (Penaeus monodon) dan udang jerbung (Penaeus merguiensis). Kepadatan tertinggi $\left(79,2 \mathrm{~kg} / \mathrm{km}^{2}\right)$ terdapat di perairan Timur Balikpapan dan terendah $\left(0,04 \mathrm{~kg} / \mathrm{km}^{2}\right)$ di Selat Makassar 
bagian tengah. Secata total, kepadatan stok udang sebesar $16,5 \mathrm{~kg} / \mathrm{km}^{2}$. Laju tangkap dan kepadatan stok udang pada perairan dangkal $(<40 \mathrm{~m})$ lebih tinggi. Untuk mengetahui status stok udang pada saat ini, disarankan untuk dilakukan pengkajian parameter populasi di daerah tersebut.

\section{PERSANTUNAN}

Tulisan ini merupakan bagian dari kegiatan penelitian "Karakteristik Biologi Perikanan, Potensi, Produksi dan Habitat Sumber Daya Ikan di perairan WPP 713" tahun 2016 oleh Balai Penelitian Perikanan Laut, Muara Baru, Jakarta.

\section{DAFTAR PUSTAKA}

Budiarti, T. W. \& Mahiswara. (2012). Analisis Kapasitas Penangkapan Perikanan Udang di Perairan Balikpapan dan Sekitarnya. dalam Suman, A., Wudianto., \& Sumiono, B (Eds): Status Pemanfaatan Sumberdaya Ikan di Perairan Selat Makassar-Teluk Bone-Laut Flores-Laut Banda. Balai Riset Perikanan Laut. IPB Press. 300 p.

Carpenter, K. E. \& Niem, V.H. (1998). The living marine resources of the Western Central Pacific Vol. 2: Cephalopods, Crustaceans, Holothurians and Sharks. Rome: FAO Species Identification Guide for Fishery Purposes. 851-971 p.

Direktorat Jenderal Perikanan Tangkap. (2015). Statistik perikanan tangkap Indonesia menurut Provinsi 2014. Direktorat Jenderal Perikanan Tangkap. 325 p.

Edrus, I. N., Prihatiningsih., \& Suprapto. (2012). Keanekaragaman ikan demersal di perairan sekitar Balikpapan dan Kota Baru. dalam Suman, A., Wudianto., \& Sumiono, B (Eds): Status Pemanfaatan Sumberdaya Ikan di Perairan Selat Makassar-Teluk Bone-Laut Flores-Laut Banda. Balai Riset Perikanan Laut. IPB Press. 300 p.

Hargiyatno, I.T., \& Sumiono, B. (2012). Kepadatan stok dan biomassa sumberdaya udang windu (Penaeus semisulcatus) dan udang dogol (Metapenaeus endeavouri) di Sub Area Aru, Laut Arafura. J. Lit. Perik. Ind, 18(1), 17-25.

Irawan, A. \& Sari, L. I. (2013). Karakteristik distribusi horizontal parameter fisika-kimia perairan permukaan di pesisir bagian Timur Balikpapan. Jurnal Ilmu Perikanan Tropis. 18(2), 21-27.

Jonsdottir, I.G., Bjornsson, H., \& Skuladottir, U. (2012). Predation by atlantic cod Gadus morhua on Northern
Shrimp Pandalus borealis in inshore and offshore areas of Iceland. Marine Progress Series, 469, 223232.

Macia, A. (2004). Juvenile penaeid shrimp density, spatial distribution and size composition in four adjacent habitats within a mangrove-fringed bay on Inhaca Island, Mozambique. Western Indian Ocean J. Mar. Sci, 3(2), 163-178.

Munga, C.N., Mwangi, S., Ong'anda, H., Ruwa, R., Manyala, J., Groenevald, J.C., Kimani, E., \& Vanreusel, A. (2013). Species composition, distribution, patterns and population structure of penaeid shrimps in Malindi-Ungwana Bay, Kenya, based on experimental bottom trawl surveys. Fisheries Research. 147, 93-102.

Naamin, N. \& Uktoselya, J. C. B. (1976). Status perikanan udang di perairan Kalimantan Selatan dan Timur. Marine Fisheries Research Report, Marine Fisheries Research Institute, 2, 1-82.

Naamin, N.A., Farid, B., Sumiono, B., Suman, A. \& Subagyo, W. (1991). Potensi dan penyebaran sumberdaya udang dalam Martosubroto, P., Naamin, N \& Malik, B.A.: Potensi dan Penyebaran Sumberdaya Ikan Laut di Perairan Indonesia. Ditjen Perikanan, Puslitbang Perikanan, Puslitbang Oseanologi-LIPI, Jakarta.

Niamaimandi, N., Arshad, A.B., Daud, S.K., Saed, R.C., \& Kiabi, B. (2007). Population dynamic of green tiger prawn, Penaeus semisulcatus (De Haan) in Bushehr Coastal Waters, Persian Gulf. Fisheries Research. 86, 105-112.

Nurulludin., Hidayat, T., \& Mamun, A. (2016). Kepadatan stok ikan demersal dan udang di Samudera Hindia Barat Sumatera pada musim peralihan II. J. Lit. Perik. Ind, 22(3), 139-146.

Pauly, D. (1980). A selection of simple methods for the assessment of tropical fish stocks (p. 54). French: FAO Fish. Circ.

Pillai, B.R., \& Diwan, A.D. (1997). Osmoregulatory adaptations of the shrimp Metapenaeus monoceros in a estuarine environment. Proc. Indian. Natn. Sci. Acad.63(4), 315-322.

Pramonowibowo., Hartoko, A., \& Ghofar, A. (2007). Kepadatan udang putih (Penaeus merguiensis De Man) di sekitar perairan Semarang. Jurnal Pasir Laut, 2(2), 18-29.

Promhom, S., Sukree, H., \& Reunchai, T. (2015). Species composition and abundance of penaeid shrimps in the 
outer Songkhla Lake of Thailand. Journal of Agricultural Technology. 11(2), 253-274.

Saeger, J., Martosubroto, P. \& Pauly, D. (1976). First report of the Indonesian-German demersal fisheries project (Result of a trawl survey in the Sunda Shelf area). Jakarta, Marine Fisheries Research Report (Special report). Contribution of the Demersal Fisheries Project no. $1,46 \mathrm{pp}$.

Somers, I. F. (1987). Sediment type as a factor in the distribution of commercial prawn species in the western gulf of Carpentaria, Australia. Aust. J. Mar. Freshw. Res, 38, 133-149 pp.

Sparre, P. \& Venema, S.C. (1992). Introduction to tropical fish stock asseessment Part 1. Manual. FAO Fish. Tech. Pap. No. 1, 376 p.
Suman, A. \& Umar. (2010). Dinamika populasi udang putih (Penaeus merguiensis De Man) di perairan Kotabaru, Kalimantan Selatan J. Lit. Perik. Ind, 16(1), 29-33.

Suman, A., \& Bintoro, G. (2009). Some population parameters of endeavour shrimp (Metapenaeus ensis de Haan) in Balikpapan surrounding waters, East Kalimantan. Ind. Fish. Res. J, 15(2), 75-79.

Suman, A., Rijal, M. \& Manadiyanto. (1993). Jenis, hubungan panjang berat, ukuran matang dan potensi perikanan udang di Perairan Kutai, Kalimantan Timur. J. Lit. Perik. Ind, 81, 76-83.

Tirtadanu., Suprapto., \& Ernawati, T. (2016). Laju tangkap, komposisi, sebaran, kepadatan stok dan biomasa udang di Laut Jawa. J. Lit. Perik. Ind, 22(4), 243-252. 